\title{
BENEFICIAMENTO DE BIOGÁS PRODUZIDO A PARTIR DE VINHAÇA PARA USO COMO GÁS NATURAL SUBSTITUTO NO ESTADO DE SÃO PAULO*
}

\author{
Caio Luca Joppert ${ }^{1}$ \\ Laiete Soto Messias ${ }^{2}$ \\ Luis Cesar Floriano Baldo ${ }^{3}$ \\ José Luis Pires Camacho ${ }^{4}$
}

\section{Resumo}

O objetivo do trabalho foi estudar a possibilidade de ajustar as características do biogás produzido a partir da fermentação de vinhaça de modo a torná-lo intercambiável com o Gás Natural (GN), ou um GN substituto (GNS) com características que permitam introduzi-lo na rede de distribuição. São considerados aspectos normativos e técnicos associados à composição química e comportamento durante processo de combustão visando o atendimento aos requisitos normativos estabelecidos para o GN. O trabalho considera a vinhaça, rejeito da produção de etanol a partir da cana-de-açúcar, como fonte para produção do biogás em razão da grande disponibilidade deste resíduo do setor sucroalcooleiro. $O$ Estado de São Paulo (ESP) é tratado com destaque, uma vez que este concentra a maior parte da produção do setor sucroalcooleiro no Brasil. Cálculos de razões de mistura tratada com gases de ajuste foram realizados para verificação das proporções necessárias que viabilizam a utilização da mistura como GNS, tendo como referência especificações da ANP. Os resultados do estudo indicam que a alternativa de geração e beneficiamento de biogás da vinhaça é uma opção tecnicamente viável de conversão de fração considerável deste resíduo do setor sucroalcooleiro em gás com características similares ao GN. Ademais, a alternativa proporciona a valoração do conteúdo orgânico do resíduo, com redução da contaminação dos solos no processo de reaproveitamento dos nutrientes nos processos de fertirrigação.

Palavras-chave: Biogás; Gás natural; Gás natural substituto; Vinhaça.

\section{UPGRADING OF BIOGAS FROM SUGAR CANE VINASSE TO BE USED AS BIOSYNGAS IN THE STATE OF SÃO PAULO}

\section{Abstract}

This paper discusses the possibility of adjusting the characteristics of biogas produced from fermentation of sugar cane vinasse to make it interchangeable with natural gas. Aspects such as normative and technical guidelines, chemical composition and combustion behavior are taken into consideration with a view of obeying the limits Brazilian natural gas standards. Vinasse, a waste of ethanol production from sugar cane, is chosen as the source of biomass for biogas production due to its large availability. Special emphasis is given to the state of São Paulo, which produces the larger part of the Brazilian ethanol and sugar. Calculations of the mixing proportion with an adjusting gas were performed in order to verify whether the final mixture would attain the natural gas specifications imposed by the Brazilian National Petroleum and Gas Agency (ANP). Results points to the production of biogas from vinasse being a technically feasible alternative for the disposal of the waste and the production of gas with similar characteristics of those from natural gas. Furthermore, this alternative adds value to the waste, reducing its polluting potential on the soil when it is used as fertilizer.

Keywords: Biogas; Natural gas; Biosyngas; Vinasse.

\footnotetext{
Eng. Químico, Engenheiro júnior, Figener Consultores de Engenharia Ltda., São Paulo, Brasil.

2 Engenheiro Mecânico, Mestre em Engenharia Mecânica, Engenheiro sênior, Figener Consultores de Engenharia Ltda.; São Paulo, Brasil.

3 Eng. Mecânico, Engenheiro sênior, Figener Consultores de Engenharia Ltda; São Paulo, Brasil.

4 Engenheiro Químico, Mestre e Doutor em Engenharia Química, Prof. Dr. do Departamento de Engenharia Química, Laboratório de Separações Térmicas e Mecânicas, Escola Politécnica, Universidade de São Paulo, São Paulo, SP, Brasil.
}

* Contribuição técnica ao $35^{\circ}$ Seminário de Balanços Energéticos Globais e Utilidades e $29^{\circ}$ Encontro de Produtores e Consumidores de Gases Industriais, 13 a 15 de agosto de 2014, São Paulo, SP, Brasil. 


\section{INTRODUÇÃO}

O setor sucroalcooleiro do Brasil tem grande numero de unidades produtoras na região centro-sul do país, sobretudo no ESP, que se destaca como maior produtor de açúcar e etanol do país (UNICA) [1]. O estado produziu mais de $50 \%$ de toda cana cultivada no país na safra de $2012 / 2013$, resultando participação de $51 \%$ do etanol e $61 \%$ do açúcar produzidos no país. Apesar dos benefícios econômicos e sociais que a esta indústria concede aos paulistanos, os impactos da produção também são marcantes, sobretudo quanto à produção de rejeitos, como bagaço da cana e a vinhaça. Enquanto o primeiro encontra destino adequado na utilização como combustível para geração de energia elétrica, o segundo ainda se configura como um problema ambiental a ser equacionado quanto à redução do impacto ambiental.

A vinhaça ou vinhoto é um subproduto da produção de etanol, gerada na etapa de destilação do vinho (caldo de cana fermentado). Autores descrevem a vinhaça como "Uma suspensão aquosa de sólidos orgânicos e minerais" [2], composta de substâncias inorgânicas solúveis (principalmente sais de potássio) e substâncias orgânicas em suspensão (DBO de 6 a $16 \times 10^{3} \mathrm{mgO} / \mathrm{l}$ ), além de álcool, açúcar e leveduras [3] e tendo características de "um líquido de cor marrom escuro, de natureza ácida ( $\mathrm{pH}$ entre 3,7 e 4,6), gerado no processo a temperatura de 80 a 100 "C" e que "possui cheiro que vai do adstringente ao nauseabundo" [4]. Quanto à disponibilidade, diversos autores [2-6] citam que são gerados 11 a $13 \mathrm{~m}^{3}$ de vinhaça para cada $\mathrm{m}^{3}$ de etanol produzido nas usinas de açúcar e álcool.

Devido ao seu alto teor de potássio, entre outros elementos químicos inorgânicos, a vinhaça é largamente utilizada como fonte de nutrientes para as lavouras de canade-açúcar (fertirrigação). Por outro lado, esta prática gera uma série de impactos ambientais como os citados por Moraes et al [5]: alta carga orgânica direcionada ao solo; salinização do solo; poluição física (pelo calor) e química (pelo baixo pH), além do odor desagradável de putrefação bastante notável nas regiões de maior concentração de culturas de cana de açúcar. A prática de fertirrigação com vinhaça no ESP é regulamentada pela CETESB através da norma técnica P4.231 [7], onde são estabelecidos um conjunto de critérios e procedimentos para aplicação de vinhaça nas culturas de cana de açúcar. Porém, já existem preocupações quanto às limitações desta prática tendo em vista a capacidade suporte do solo, e que podem restringir em certas regiões, o desenvolvimento e a ampliação das atividades industriais do setor.

A biodigestão da vinhaça como alternativa de melhor disposição deste rejeito é abordada devido ao grave problema ambiental que esta tem se tornado e devido ao alto potencial de geração de energia pelo processo, na forma de biogás produzido pela fermentação anaeróbica. O biogás, após tratado e corrigido com gases de ajuste, pode ser injetado diretamente na rede de distribuição de GN de forma a aumentar a produção interna deste insumo energético e possibilitar uma maior amplitude de uso para o mesmo. O trabalho aborda exclusivamente as questões e relativas ao beneficiamento do biogás com objetivo de elevá-lo a uma qualidade suficiente para se tornar um GNS, comumente denominado biometano (biosyngas).

Estudos sobre biodigestão da vinhaça por bactérias anaeróbicas (metanogênicas) são desenvolvidos desde a década de 80 , mas, os preços relativos dos combustíveis e a tecnologia disponível não tornaram a sua produção um processo economicamente viável no país. Não obstante, no cenário atual, onde se busca o aumento da participação de fontes renováveis na matriz energética, a preocupação

* Contribuição técnica ao $35^{\circ}$ Seminário de Balanços Energéticos Globais e Utilidades e $29^{\circ}$ Encontro de Produtores e Consumidores de Gases Industriais, 13 a 15 de agosto de 2014, São Paulo, SP, Brasil. 


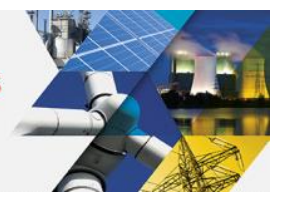

com questões ambientais e o aprimoramento tecnológico consideram-se as possibilidades da utilização da biodigestão como forma de disposição. A biodigestão da vinhaça, segundo Craveiro [8] consome cerca de 95\% da DBO do rejeito sem afetar seu teor de potássio, além de ter temperatura e pH ajustados, de modo que, após a extração da matéria orgânica, o efluente do biorreator pode ainda continuar sendo utilizado como fonte de fertilizantes, de forma menos agressiva ao solo e com maior valor agregado.

\subsection{Revisão Bibliográfica}

Nesta seção, será relatada uma breve revisão literária sobre o tema biogás, focando nas características, processo de beneficiamento e uso do mesmo.

\subsubsection{Características gerais do biogás}

Segundo a CETESB [9], o biogás é "uma mistura gasosa resultante da degradação anaeróbia da matéria orgânica (...) formada principalmente por metano e dióxido de carbono". Conforme pontuado por diversos autores, a composição do biogás é muito dependente da fonte de matéria orgânica processada. Geralmente, apresentam-se composições médias, conforme evidenciado na Tabela 1. Além de $\mathrm{CH}_{4}$ e $\mathrm{CO}_{2}$, $\mathrm{o}$ biogás apresenta, em menores proporções, $\mathrm{H}_{2} \mathrm{~S}, \mathrm{H}_{2}$ e umidade.

Tabela 1: Composição média do biogás segundo diversos autores

\begin{tabular}{|c|c|c|c|c|}
\hline Compostos & $\%$ vol [4] & $\%$ vol [11] & $\%$ vol [12] & $\%$ vol $[10]$ \\
\hline $\mathrm{CH}_{4}$ & 40 a 70 & 40 a 75 & 50 a 75 & 50 a 75 \\
\hline $\mathrm{CO}_{2}$ & 25 a 40 & 25 a 40 & 25 a 40 & 25 a 45 \\
\hline $\mathbf{N}_{2}$ & 0,5 a 2,5 & 0,5 a 2,5 & 0,5 a 2,5 & 0 a 2 \\
\hline $\mathrm{O}_{2}$ & 0,1 a 1 & 0,1 a 1 & 0,1 a 1 & 0 a 2 \\
\hline $\mathrm{H}_{2} \mathrm{~S}$ & 0,1 a 0,5 & 0,1 a 0,5 & 0,1 a 0,5 & 0,002 a 2 \\
\hline $\mathrm{NH}_{3}$ & 0,1 a 0,5 & 0,1 a 0,5 & 0,1 a 0,5 & - \\
\hline $\mathrm{CO}$ & 0 a 0,1 & 0 a 0,1 & - & - \\
\hline $\mathrm{H}_{2}$ & 1 a 3 & 1 a 3 & 1 a 3 & 0 a 1 \\
\hline
\end{tabular}

\subsubsection{Beneficiamento do biogás}

O beneficiamento do biogás se faz necessário para remoção de três substâncias contaminantes principais: $\mathrm{H}_{2} \mathrm{~S}, \mathrm{CO}_{2}$ e $\mathrm{H}_{2} \mathrm{O}$. O gás sulfídrico, além de tóxico nas concentrações do biogás "cru", torna-se corrosivo na presença de umidade e pode prejudicar a remoção de outros contaminantes. A umidade, por sua vez, pode se condensar em tubulações e equipamentos, provocando corrosão ou formação de gelo. $\mathrm{O} \mathrm{CO}_{2}$ é inerte na combustão, reduzindo o poder calorífico do biogás e ocupando volume de estocagem $[10,12,15]$. Basicamente, o processo de limpeza do biogás se divide em três etapas sucessivas: remoção de contaminantes de menor concentração, remoção da umidade e $\mathrm{H}_{2} \mathrm{~S}$ (secagem e dessulfurização) e a remoção de $\mathrm{CO}_{2}$ (sweetening).

A secagem do biogás pode se dar por compressão ou por resfriamento do gás, além de ser possível a adsorção da umidade em leitos de silicatos ou zeólitas ou a absorção em soluções de glicóis. A remoção de umidade é mais eficiente nos dois últimos processos citados, que são mais dispendiosos, aplicáveis, portanto, para grandes volumes de biogás [10,14,15].

* Contribuição técnica ao $35^{\circ}$ Seminário de Balanços Energéticos Globais e Utilidades e $29^{\circ}$ Encontro de Produtores e Consumidores de Gases Industriais, 13 a 15 de agosto de 2014, São Paulo, SP, Brasil. 
A dessulfurização pode ocorrer por processos físicos, químicos ou biológicos: os métodos físicos baseiam-se na absorção do gás em água ou soluções de $\mathrm{NaOH}$; os químicos baseiam-se na precipitação do enxofre no biorreator por meio do uso de sais de ferro ou pelo uso de matrizes de materiais ferrosos ou carvão ativado para captura e transformação do $\mathrm{H}_{2} \mathrm{~S}$. Os métodos biológicos baseiam-se no uso de bactérias redutoras de enxofre para reduzí-lo no meio da fermentação ao estado elementar. À exceção da remoção por meio de matrizes ferrosas e carvão ativado, a remoção do enxofre não atinge os níveis para o biogás ser considerado limpo; exceto pelo uso de dessulfurização biológica, todos os métodos utilizam insumos em quantidade elevada (soluções químicas, água ou leitos de adsorção) [10,14,15].

$\mathrm{Na}$ etapa de redução do teor de $\mathrm{CO}_{2}$ os métodos mais utilizados são: absorção em água ou soluções químicas e adsorção em pressão flutuante (PSA). A absorção promove captura do gás carbônico em colunas de lavagem, que podem empregar água, soluções de polietilenoglicol, metanol ou aminas como meio absorvente; a técnica de PSA promove captura do gás contaminante em leitos de zeólitas ou carvão ativado em pressão elevada, promovendo a dessorção do gás por posterior diminuição da pressão. Comparativamente, todas as técnicas citadas são relativamente dispendiosas, à exceção da adsorção por PSA; a eficiência de separação, expressa pelo teor final de $\mathrm{CH}_{4}$, é moderada com absorção em água ou PEG e com adsorção por PSA (de 96 a $97 \%$ de $\mathrm{CH}_{4}$ no gás limpo) e muito elevada quando se emprega absorção com aminas (ao redor de $99 \%$ de $\mathrm{CH}_{4}$ no gás limpo).

Deve-se ressaltar que a escolha da técnica de lavagem nem sempre envolve apenas a eficiência de remoção, mas também o uso final do biogás: técnicas que realizam dessulfurização bruta podem ser indicadas para quando o uso do biogás é a combustão direta em caldeiras; técnicas que disponibilizam o gás em alta pressão após o processo (como a maioria das técnicas de absorção ou adsorção) podem ser indicadas quando se objetiva injetar o gás diretamente na rede [10].

Dependendo da utilização do biogás, é possível fazer ajustes do poder calorífico e do índice de Wobbe (parâmetro relevante na intercambiabilidade de gases combustíveis) mediante a mistura prévia com ar ou gases combustíveis ricos em frações de hidrocarbonetos mais pesados (por exemplo, GLP) [10].

\subsubsection{Utilização do biogás}

No mundo a produção de biogás a partir de resíduos agrícolas é praticada na Europa e Estados Unidos, sendo que a primeira concentra cerca de $77 \%$ das usinas atuais. Deste montante, $42 \%$ se encontram na Suécia, 33\% na Alemanha e 15\% na Suíça [14]. Nestes países, o biogás é geralmente [10] utilizado em caldeiras como combustível auxiliar / complementar e em motores para geração de energia elétrica para consumo interno ou para exportação e mais recentemente utilizado como gás natural substituto, injetado na rede de distribuição de gás. No entanto, para que estes usos sejam possíveis, o biogás precisa ser beneficiado de modo a reduzir o teor compostos indesejáveis e valores de poder calorífico em níveis aceitáveis de acordo com o uso.

No Brasil a prática ainda é pouco disseminada, com alguns casos mais recentes aplicados à vinhaça voltados à produção de biogás queimados diretamente em flares ou no interior de câmaras de combustão (caldeiras) das usinas, ou utilizado diretamente em motores para geração de energia elétrica [13].

* Contribuição técnica ao $35^{\circ}$ Seminário de Balanços Energéticos Globais e Utilidades e $29^{\circ}$ Encontro de Produtores e Consumidores de Gases Industriais, 13 a 15 de agosto de 2014, São Paulo, SP, Brasil. 


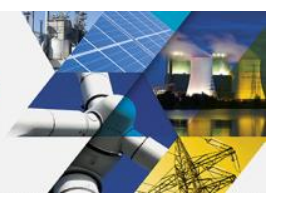

\subsubsection{Injeção de biogás em redes de distribuição}

A prática da injeção de biogás tratado em redes de distribuição é comum na Europa, onde o biogás é utilizado não só como fonte de geração de energia elétrica, mas também como fonte combustível para automóveis e sistemas de aquecimento [10]. Experiências positivas de injeção de biogás em redes de distribuição como GNS são encontradas na Alemanha, Suécia, Áustria e Suíça, entre outros [10,16]. No caso alemão, que é o caso onde há maior avanço na prática de injeção de gás na rede, existem diretrizes específicas que estabelecem a composição de gás a ser introduzido na rede, a qualidade que o biogás deve ter para poder ser injetado na rede e as responsabilidades do distribuidor de gás quanto à cobrança e qualidade do gás de saída, além de programas de estímulo e legislações que incentivam produtores locais de biogás como, por exemplo, a obrigatoriedade das distribuidoras de gás de injetarem o biogás, após beneficiamento e pressurização, na rede de distribuição quando a demanda por outros usos se torna baixa. A injeção de biogás na rede requer que o mesmo seja levado até a pressão da rede de distribuição (que pode chegar a 200 bar em gasodutos principais).

Dentre as vantagens de se injetar biogás na rede de distribuição, pode-se citar principalmente a diversificação do uso da fonte energética e a possibilidade de levar o gás até locais onde se encontram usinas de cogeração, onde seu potencial energético pode ser aproveitado com maior eficiência. Outra vantagem é a possibilidade de utilização de "smart grids" como forma de se contornar a disponibilidade sazonal de fontes de energia não-convencionais. Como desvantagens, têm-se os custos adicionais para tratamento do biogás e a energia dispendida na compressão do mesmo, além do risco de liquefação de compostos mais pesados devido ao aumento da pressão nas redes de distribuição [10].

\section{MATERIAIS E MÉTODOS}

Para elaboração deste estudo, foi consultada a literatura sobre vinhaça, sua biodigestão e biogás, bem como se pesquisou a experiência de outros países no setor de geraçãoe uso de biogás. Normas dos órgãos reguladores brasileiros (CETESB e ANP) foram utilizadas como base para os cálculos que serão apresentados adiante. A análise do potencial do ESP para geração de biogás foi realizada combinando-se a ferramenta de exploração geográfica Google Earth com publicações técnicas sobre o setor de gás e energia no ESP (ARSESP, CEPE) e com dados estatísticos divulgados em anuários e boletins técnicos do setor sucroalcooleiro.

\section{RESULTADOS E DISCUSSÃO}

Duas discussões pertinentes serão abordadas nesta seção: o aspecto da viabilidade técnica do beneficiamento e correção de parâmetros físico-químicos do biogás de forma a este ser intercambiável com GN e potencial do ESP quanto à produção de biogás, levando em conta a produção de vinhaça e o posicionamento de usinas produtoras de etanol em relação à gasodutos existentes.

\subsection{Balanços do Beneficiamento e Mistura do Biogás}

Para que o biogás possa ser utilizado como um substituto do gás natural na rede de distribuição de GN é preciso que este atinja os requisitos estabelecidos pelas ANP -

* Contribuição técnica ao $35^{\circ}$ Seminário de Balanços Energéticos Globais e Utilidades e $29^{\circ}$ Encontro de Produtores e Consumidores de Gases Industriais, 13 a 15 de agosto de 2014, São Paulo, SP, Brasil. 


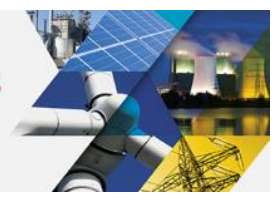

Agência Nacional de Petróleo quanto à composição química e índice de Wobbe. A norma da ANP para gás natural é apresentada na Tabela 2, onde destacam-se as baixas concentrações de $\mathrm{H}_{2} \mathrm{~S}$ e de $\mathrm{CO}_{2}$ permitidas. Cabe observar que os valores são referenciados às condições de $1 \mathrm{~atm}$ e $25^{\circ} \mathrm{C}$.

Tabela 2: Especificação do gás natural (Resolução n 16 da ANP de 17/06/2008)

\begin{tabular}{c|c|c|c|c}
\hline \multirow{2}{*}{ Característica } & \multirow{2}{*}{ Unidade } & \multicolumn{3}{|c}{ Limites de acordo com região } \\
\cline { 3 - 5 } & & Norte & Nordeste & Outras \\
\hline Poder Calorífico Superior & $\mathrm{MJ} / \mathrm{m}^{3}$ & 34 a 38 & 35 a 43 & 35 a 43 \\
\hline Índice de Wobbe & $\mathrm{MJ} / \mathrm{m}^{3}$ & $40,5 \mathrm{a} 45$ & 46,5 a 53,5 & 46,5 a 53,5 \\
\hline $\mathrm{CH}_{4}$ (mín) & $\%$ vol & 68 & 85 & 85 \\
\hline $\mathrm{C}_{2} \mathrm{H}_{6}$ (máx) & $\%$ vol & 12 & 12 & 12 \\
\hline $\mathrm{C}_{3} \mathrm{H}_{8}$ (máx) & $\%$ vol & 3 & 6 & 6 \\
\hline $\mathrm{C}_{4} \mathrm{H}_{10}$ e superiores (máx) & $\%$ vol & 1,5 & 3 & 3 \\
\hline $\mathrm{O}_{2}$ (máx) & $\%$ vol & 0,8 & 0,5 & 0,5 \\
\hline Inertes ( $\mathrm{N}_{2}$ e outros, máx) & $\%$ vol & 18 & 8 & 6 \\
\hline $\mathrm{CO}_{2}$ (máx) & $\%$ vol & 3 & 3 & 3 \\
\hline $\mathrm{H}_{2} \mathrm{~S}$ (máximo) & $\mathrm{mg} / \mathrm{m}^{3}$ & 10 & 13 & 10 \\
\hline
\end{tabular}

Os parâmetros relacionados à combustão como poder calorífico superior e índice de Wobbe precisam ser ajustados para se adequarem à norma, para o qual geralmente se utiliza GLP como gás de ajuste. No entanto, os teores de propano e butano permitidos no GN pela ANP são, também, bastante baixos. É necessário aferir a proporção de mistura de GLP com biogás beneficiado que atinge a norma da agência reguladora por meio de balanços de mistura e, adicionalmente, averiguar se os parâmetros ligados à combustão também se enquadram na mesma.

Para o balanço, consideram-se como hipóteses: que o GLP é uma mistura de composição de 56,7\% de propano e 43,3\% em base molar (iguais proporções mássicas); que o biogás "cru" (contaminado) é composto de $\mathrm{CH}_{4}, \mathrm{CO}_{2}, \mathrm{H}_{2} \mathrm{~S}$ e gases inertes; que as perdas de $\mathrm{CH}_{4}$ no beneficiamento são desprezíveis e que a mistura final é composta de todos os elementos citados, com a condição de contorno de que as frações molares de butano, gás carbônico e gás sulfídrico sejam aquelas determinadas pela norma da ANP (6\%, 3\% e praticamente zero, respectivamente). Dados adicionais, como massa molar dos compostos e seus poderes caloríficos foram retirados da literatura [17].

Os balanços de mistura resultam no seguinte equacionamento (equações (1) a (5)):

$$
\begin{aligned}
& V_{b i o, l}=13,38 . V_{G L P} \\
& V_{b i o, c}=\frac{12,95 \cdot V_{G L P}}{r} \\
& r=\frac{1}{1-c-s} \\
& P C S_{\text {bio }}=35,762 . r . m+7,827 \\
& W b_{\text {bio }}=\frac{35,762 \cdot r \cdot m+7,827}{(1,062-0,397 \cdot r \cdot m)^{0,5}}
\end{aligned}
$$

Onde $V_{b i o, c}, V_{b i o, l}$ e $V_{G L P}$ são, respectivamente, os volumes de biogás "cru" (produzido pela fermentação), o volume de biogás "limpo" (após processo de beneficiamento) e o volume de GLP a ser adicionado na mistura final $\left(\mathrm{m}^{3}\right) ; P C S_{b i o}$ é o poder calorífico superior da mistura final e $W b_{b i o}$ é o Índice de Wobbe da mesma (ambos dados em $\mathrm{MJ} / \mathrm{Nm}^{3}$ ); $r$ é o fator de ajuste do biogás "cru", representando quantitativamente 0 processo de beneficiamento; $m, c$ e $s$ são as frações molares de $\mathrm{CH}_{4}, \mathrm{CO}_{2}$ e $\mathrm{H}_{2} \mathrm{~S}$ no biogás "cru". As frações de $\mathrm{CO}_{2}$ e $\mathrm{H}_{2} \mathrm{~S}$ a serem retiradas pelo processo de beneficiamento ( $R_{\mathrm{CO} 2}$ e $R_{\mathrm{H} 2 S}$ ) podem ser calculados pelas equações (6) e (7).

* Contribuição técnica ao $35^{\circ}$ Seminário de Balanços Energéticos Globais e Utilidades e $29^{\circ}$ Encontro de Produtores e Consumidores de Gases Industriais, 13 a 15 de agosto de 2014, São Paulo, SP, Brasil. 


$$
R_{\text {CO2 }}=1-\frac{0,033}{r . c} \quad(6) \quad R_{H 2 S}=1-\frac{7,972.10^{-6}}{r . s}
$$

$\mathrm{Na}$ Figura 1, apresenta-se um diagrama que representa a equação (4). Os limites definidos são os da ANP, com folga de $5 \%$ do valor limite da norma. A Literatura indica que o biogás "cru" produzido a partir de vinhaça em reatores tipo UASB (leito ascendente) atinge rendimentos de cerca de $14 \mathrm{~m}^{3}$ de metano por $\mathrm{m}^{3}$ de vinhaça fermentada, sendo que cerca de $65 \%$ em volume do biogás é $\mathrm{CH}_{4}[9,11,13]$. Diversas outras fontes indicam que os teores de $\mathrm{CO}_{2}$ e $\mathrm{H}_{2} \mathrm{~S}$ para biogás produzido a partir de resíduos agrícolas variam entre 30 e 20\% e de 0,1 a 0,02\%. Tomando valores médios para estes dois últimos compostos, podemos estimar que o biogás produzido pela vinhaça, após tratamento adequado e mistura com GLP, tem poder calorífico superior de 39,1 $\mathrm{MJ} / \mathrm{m}^{3}$ e Índice de Wobbe de 46,2 $\mathrm{MJ} / \mathrm{m}^{3}$, se enquadrando, assim, nas normas da ANP. Mas, para tal, $96 \%$ do $\mathrm{CO}_{2}$ do gás deve ser retirado e mais de $99 \%$ do $\mathrm{H}_{2} \mathrm{~S}$ deve ser removido pelo sistema de limpeza.

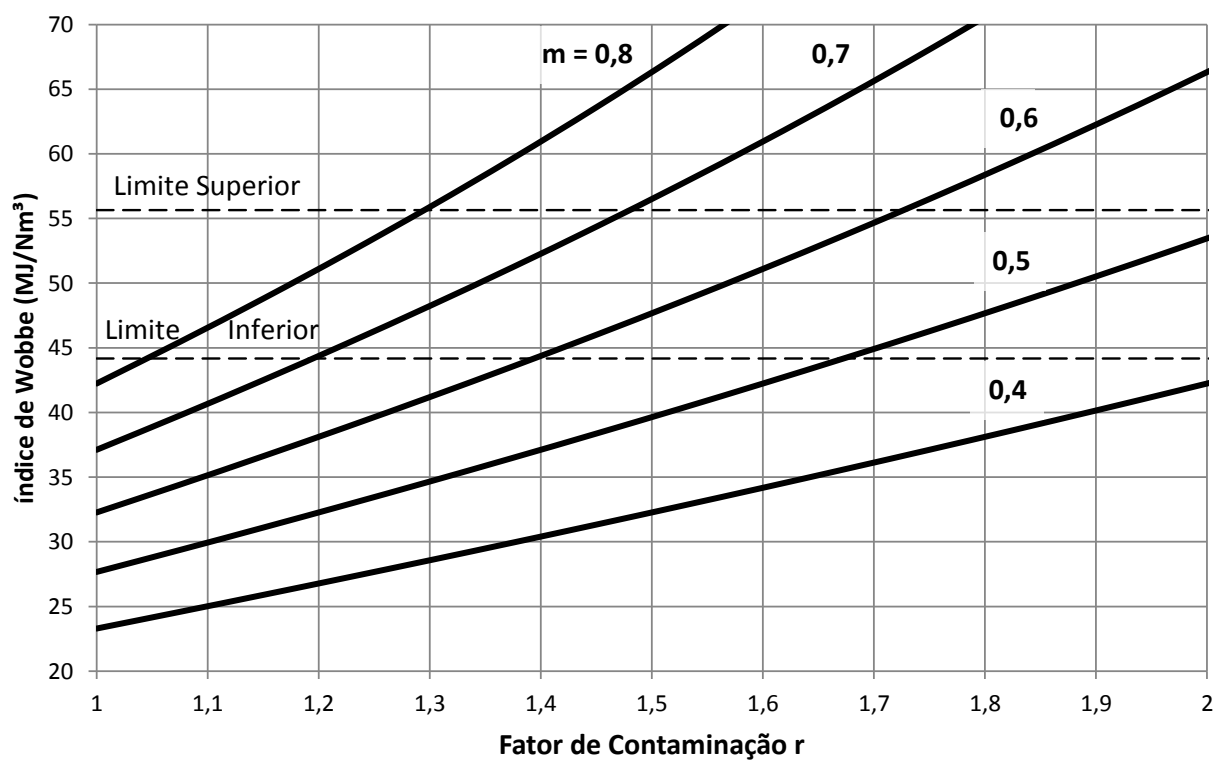

Figura 1: Índice de Wobbe da mistura de GLP com o biogás beneficiado

Outros pontos a serem ressaltados incluem: conforme descrito na equação (1), retiram-se combustíveis fósseis da matriz energética em proporção 13 vezes menor do que o volume aportado de GN substituto, de forma a energia aportada como GN substituto é mais de 5 vezes maior do que a retirada na forma de combustíveis fósseis. Outro ponto a ser ressaltado é que a liberação de $\mathrm{CO}_{2}$ pelo processo de beneficiamento não representa um agravante ambiental, dado que este carbono é biogênico. Por fim, o processo de biodigestão da vinhaça evita que o descarte do resíduo no solo contamine lençóis freáticos com $\mathrm{DBO}$, além de mitigar o processo de formação de metano e óxidos de nitrogênio (cujos efeitos de gás estufa são 21 e 296 vezes mais potente que do $\mathrm{CO}_{2}$ [5]) por fermentação ao ar livre.

\subsection{Potencial de Utilização do Biogás no Estado de São Paulo}

Dos usos citados para o biogás, as finalidades de cogeração ou geração de energia elétrica se mostram pouco interessantes para o setor sucrolacooleiro paulista, especificamente, dado que o bagaço de cana já se figura como uma fonte suficiente de combustível para que as usinas sejam autossuficientes em termos de energia [2].

* Contribuição técnica ao $35^{\circ}$ Seminário de Balanços Energéticos Globais e Utilidades e $29^{\circ}$ Encontro de Produtores e Consumidores de Gases Industriais, 13 a 15 de agosto de 2014, São Paulo, SP, Brasil. 


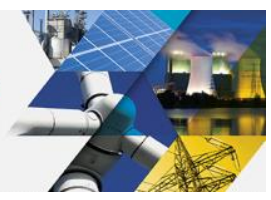

Já a alternativa de injeção do GNS na rede de gás comercializada no ESP se apresenta como uma possibilidade mais interessante.

No Brasil, a experiência com biogás ainda é modesta, apesar do grande potencial existente. No entanto, estímulos governamentais, como portarias de programas de incentivo e facilidades fiscais vêm sido criados nos últimos anos para fomentar a pesquisa e produção de biogás. Um exemplo é o do Governo do Estado de São Paulo que, com o decreto $n^{\circ} 58.659$ de 4/12/2012 instituiu o "Programa Paulista de Biogás", denominando de "biometano" o biogás cuja composição for compatível com a referida resolução ANP (tabela 2), destacando o "grande potencial de geração de biometano no setor sucroenergético", apontando para a possibilidade de misturá-lo com o gás canalizado comercializado no Estado. Já ao final do ano de 2013, o Conselho Estadual de Política Energética (CEPE) aprovou um marco regulatório no qual permite a injeção de biogás na rede de distribuição de $\mathrm{GN}$, segundo o qual as empresas concessionárias de GN terão que "aproveitar até $10 \%$ da geração de biogás disponível em suas regiões de concessão, desde que os fornecedores garantam a qualidade" [18].

$\mathrm{Na}$ Figura 2 destacam-se no território do ESP as regiões de concessão de distribuição de GN, a localização das principais usinas sucroalcooleiras e os principais dutos para transporte de etanol e GN, bem como os que estão previstos nos projetos de ampliação das redes.

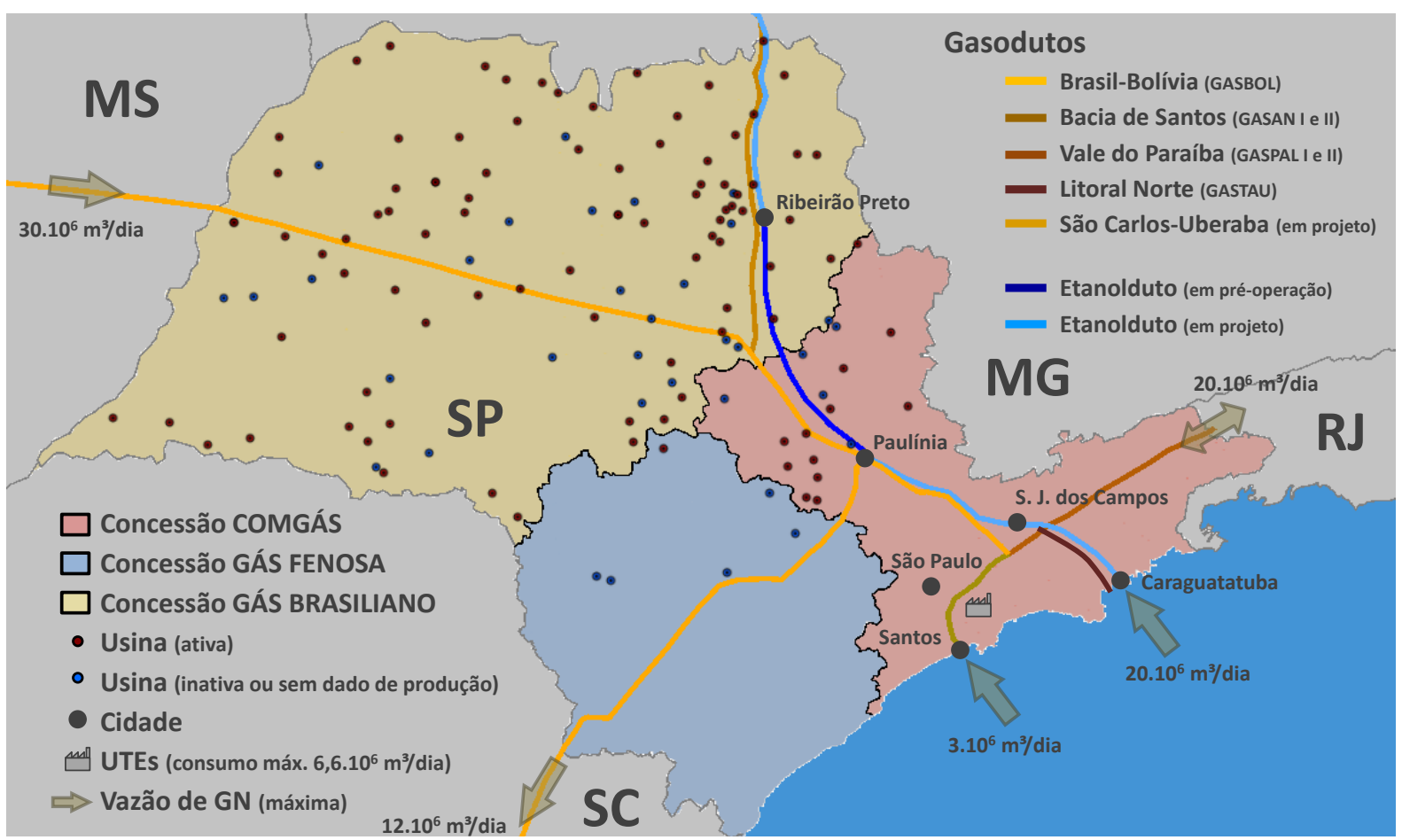

Figura 2: Panorama do Estado de São Paulo quanto à localização de usinas de etanol e transporte dutoviário $[19,20,21]$.

É notável a maior concentração de usinas na região norte e noroeste do Estado, sobretudo nas proximidades da cidade de Ribeirão Preto e Araraquara. Algumas usinas encontram-se, inclusive, próximas a gasodutos já instalados ou que têm projeto de instalação existente favorecendo a injeção do a sua injeção na rede. A Tabela 3 apresenta o potencial de produção de biogás para as áreas de concessão de distribuição de GN, segundo dados de produção das principais destilarias do ESP [20] (cabe observar que as usinas selecionadas representam $82 \%$ da produção do

* Contribuição técnica ao $35^{\circ}$ Seminário de Balanços Energéticos Globais e Utilidades e $29^{\circ}$ Encontro de Produtores e Consumidores de Gases Industriais, 13 a 15 de agosto de 2014, São Paulo, SP, Brasil. 
ESP). Para as produções de vinhaça e potencial produção de biogás, utilizam-se os seguintes parâmetros: $12 \mathrm{~m}^{3}$ de vinhaça por $\mathrm{m}^{3}$ de etanol produzido; $14 \mathrm{~m}^{3}$ de metano por $\mathrm{m}^{3}$ de vinhaça fermentada e $65 \%$ em volume de metano no biogás produzido. Ademais, assume-se que a duração de safra de cana-de-açúcar é de 9 meses. Utilizando as equações (1) a (3), calcula-se o potencial volume de GNS a ser disponibilizada. Tomando como base a proposta do CEPE de que as concessionárias aproveitem $10 \%$ do potencial de produção de biogás em suas áreas de concessão, calcula-se, por fim, a razão entre o gás distribuído atualmente e o acréscimo que seria promovido pela produção de biogás em cada área de concessão.

Tabela 3: Produção potencial de biogás no Estado de São Paulo na safra 2011/12.

\begin{tabular}{|c|c|c|c|c|c|}
\hline $\begin{array}{c}\text { Área de } \\
\text { Concessão }\end{array}$ & $\begin{array}{c}\text { Volume de } \\
\text { GN } \\
\text { distribuído } \\
\left(10^{6} \mathrm{~m}^{3} / \mathrm{dia}\right)\end{array}$ & $\begin{array}{l}\text { Produção } \\
\text { de etanol } \\
\left(10^{3} \mathrm{~m}^{3} / \mathrm{sf}\right)\end{array}$ & $\begin{array}{l}\text { Volume de } \\
\text { GNS } \\
\text { aportado à } \\
\text { rede } \\
\left(10^{6} \mathrm{~m}^{3} / \text { dia }\right)\end{array}$ & $\begin{array}{c}\text { Volume de } \\
\text { GLP para } \\
\text { mistura (10 } \\
\text { m³/dia) }^{6}\end{array}$ & $\begin{array}{l}\text { Razão } \\
\text { GNS/GN }\end{array}$ \\
\hline Comgas & 15,32 & 872 & 0,125 & 0,009 & $0,81 \%$ \\
\hline Gás Fenosa & 1,22 & 109 & 0,016 & 0,001 & $1,95 \%$ \\
\hline $\begin{array}{c}\text { Gás } \\
\text { Brasiliano }\end{array}$ & 0,87 & 8.294 & 1,185 & 0,082 & $136,2 \%$ \\
\hline Total ESP* & 17,41 & 11.598 & 1,657 & 0,115 & $9,51 \%$ \\
\hline
\end{tabular}

Tomando o ESP como volume de controle, a produção de biogás significaria uma geração interna, representando, em termos médios, 9,5\% do total da demanda atual de GN no Estado. Tendo em vista que as projeções preveem crescimento de 3 vezes na demanda de GN no ESP para 2020 [19], a viabilização do aproveitamento biogás é um fator relevante. É interessante notar, ainda, que na área de concessão onde há menor consumo de GN há o maior potencial para produção de GNS.

Outro ponto a ser ressaltado é a proximidade de algumas usinas dos gasodutos existentes ou em projeto. Não obstante a grande dispersão de usinas observada ao longo do território do ESP existe um número considerável de unidades produtoras de etanol que se situam relativamente próximas aos gasodutos, o que viabilizaria o aproveitamento do biogás via injeção do GNS na rede de pelo menos 19 e $30 \%$ do potencial estimado de produção de biogás das áreas de concessão Comgas e Gás Brasiliano, respectivamente. Em particular, na área de concessão Gás Brasiliano, $10 \%$ do potencial da região estão próximos do GASBOL e $20 \%$ encontram-se nas circunvizinhanças do projeto de gasoduto entre São Carlos e Uberaba. Desta forma, a proposta de utilização de $10 \%$ do potencial de produção de biogás poderia ser suprida por apenas estas usinas. Ademais, na perspectiva de ampliação da rede de etanoldutos até as usinas, é razoável considerar a possibilidade de instalação simultânea de dutos coletores de GNS das usinas para conexões destas às redes de distribuição de GN existentes e aquelas em fase de projeto.

\section{CONCLUSÃo}

A análise de dados de diferentes fontes permitiu elaborar um panorama do potencial de produção de biogás em São Paulo. O Estado apresenta um potencial apreciável para produção de biogás a partir da vinhaça, dado que neste se concentra o maior

* Contribuição técnica ao $35^{\circ}$ Seminário de Balanços Energéticos Globais e Utilidades e $29^{\circ}$ Encontro de Produtores e Consumidores de Gases Industriais, 13 a 15 de agosto de 2014, São Paulo, SP, Brasil. 


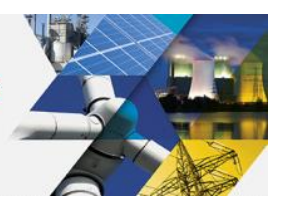

volume da produção sucroalcooleira nacional e por possuir uma extensa rede de distribuição de Gás Natural já implantada ou em fase de projeto.

A injeção de gás natural substituto na rede de distribuição do Estado permitiria um aumento considerável na disponibilidade de gás, frente a uma demanda crescente. A presença de usinas próximas à rede de distribuição é um fator positivo, que contribui para a viabilidade do aproveitamento do potencial de produção de biogás. Enquanto a viabilidade econômica da instalação de unidades produtoras de biogás e de injeção na rede estará condicionada aos custos envolvidos no beneficiamento do biogás "cru" e pressurização do gás natural substituto, a adoção da prática de injeção de biogás na rede de distribuição em outros países se mostra viável mediante os incentivos e regulamentação governamental. Desta forma, programas de fomento à produção de biogás são essenciais para que uma situação semelhante possa ser adotada no Brasil.

Por fim, o processo de biodigestão da vinhaça agrega valor ao resíduo e torna-o menos agressivo ao meio ambiente sem deteriorar suas características nutricionais que justificam o uso da prática de fertirrigação.

\section{Agradecimentos}

Ficam registrados os agradecimentos aos colegas da Escola Politécnica da Universidade de São Paulo e aos engenheiros da equipe técnica da FIGENER que colaboraram para a confecção deste trabalho.

\section{REFERÊNCIAS}

1 União Nacional Da Indústria Da Cana-De-Açúcar. Histórico de produção e moagem por produto [página da internet]. São Paulo: UNICA, 2014 [acesso em Abril de 2014].

Disponível em: www.unicadata.com.br/historico-de-producao-e-moagem.php

2 Camargo CA. Conservação de Energia na Indústria do Açúcar e do Álcool. São Paulo: IPT, 1990.

3 Centro de Tecnologia Promon. Vinhoto: Avaliação Técnico-Econômica de Processos de Reaproveitamento, Vol. 1. São Paulo: PROMON, 1979.

4 Salomon KR. Avaliação Técnico-Econômica e Ambiental da Utilização do Biogás Proveniente da Biodigestão da Vinhaça em Tecnologias para Geração de Eletricidade [tese de doutorado]. Itajubá: Universidade Federal de Itajubá, 2007.

5 Moroaes Bs, Zaiat M, Bonomi A, Mantelatto Pe, Cavalett O, Pavanello LG, et al. Anaerobic digestion of vinasse from sugarcane biorefineries in Brazil from energy, environmental, and economic perspectives: Profit or expense? Applied Energy. 2013; 113: 825-835.

6 Lora Ees, Venturini OJ. Biocombustíveis, Vol, 1. Rio de Janeiro: Interciência, 2012.

7 Companhia de Tecnologia e Saneamento Ambiental. Norma P4.231 - Vinhaça: critérios e procedimentos para aplicação no solo agrícola. São Paulo: CETESB, 2006.

8 Craveiro AM. Produção de Metano a Partir de Vinhaça. São Paulo: IPT, 1983.

9 Companhia de Tecnologia e Saneamento Ambiental. Biogás: Pesquisas e projetos no Brasil. São Paulo: Secretaria do Meio Ambiente do Estado de São Paulo, 2006.

10 Fachagentur Nachwachsende Rohstoffe. Guia Prático do Biogás - Tradução da 5a edição de Leiftaden Biogas. Güzlow: Ministério da Nutrição, Agricultura e Defesa do Consumidor da Alemanha em cooperação com o Ministério das Cidades do Brasil, 2010.

11 Salomon KR, Lora EES. Estimate of the electric energy generating potential for different sources of biogas in Brazil. Biomass and Bioenergy. 2009; 33: 1101 - 1107.

* Contribuição técnica ao $35^{\circ}$ Seminário de Balanços Energéticos Globais e Utilidades e $29^{\circ}$ Encontro de Produtores e Consumidores de Gases Industriais, 13 a 15 de agosto de 2014, São Paulo, SP, Brasil. 
12 Cassini ST. Digestão de resíduos sólidos orgânicos e aproveitamento do biogás. Rio de Janeiro: PROSAB, 2003.

13 Gerhard E, Derenzo S, Antonoff HB, Souza LAAA, Sin Yu A, Mazzonetto A, et al. Brazilian Bio-Fuels Production Scenario (Biogas, Biomethane And Biosyngas). São Paulo: IPT, 2013.

14 Petersson A, Wellinger A. Biogas upgrading Technologies - developments and innovations. Malmö/Aadorf: IEA Bioenergy, 2009.

15 Ryckebosch E, Drouillon, Vervaeren $\mathrm{H}$. Techniques for transformation of biogas to biomethane. Biomass and Bioenergy. 2009; 35: 1633 - 1645.

16 Miltner M, Makaruk A, Harasek M. Application Of Gas Permeation For Biogas Upgrade Operational Experiences Of Feeding Biomethane Into The Austrian Gas Grid. Viena, 200[?].

17 Van Wylen GJ; Sonntag RE. Fundamentos da Termodinâmica Clássica. São Paulo: Edgard Blücher, 1980

18 Energia Hoje. Companhias de gás de São Paulo vão distribuir biogás [página da internet] São Paulo: Energia Hoje, 2013 [acesso em Abril de 2014]. Disponível em: energiahoje.editorabrasilenergia.com/news/gas/logisticacomercializacao/2013/10/companhias-de-gas-de-sao-paulo-vao-distribuir-biogas455899.html

19 Agência Reguladora de Saneamento e Energia do Estado dDe São Paulo. Boletim Bimestral ARSESP n¹ Janeiro/2013. São Paulo: ARSESP, 2013.

20 Análise Energia. Anuário 2013. São Paulo: Análise Editorial, 2013.

21 Conselho Estadual De Política Energética. Plano Paulista de Energia 2020. São Paulo: CEPE/Secretaria de Energia, 2012.

* Contribuição técnica ao $35^{\circ}$ Seminário de Balanços Energéticos Globais e Utilidades e $29^{\circ}$ Encontro de Produtores e Consumidores de Gases Industriais, 13 a 15 de agosto de 2014, São Paulo, SP, Brasil. 